\title{
Determinants of Inpatient Satisfaction on Hospital Services in a Government Tertiary Care Center
}

Smita Kumari Panda ${ }^{1}$, Sushree Priyadarsini Satapathy ${ }^{2}$, Prakash Chandra Panda ${ }^{3}$, Kulwant Lakra ${ }^{4}$, Shilpa Karir ${ }^{2}$, Jasmin Nilima Panda

${ }^{1}$ Associate Professor, ${ }^{2}$ Senior Resident, ${ }^{3}$ Professor and Head, ${ }^{4}$ Assistant Professor, ${ }^{5}$ Postgraduate Student, Department of Community Medicine, Veer Surendra Sai Institute Of Medical Sciences and Research, Burla, Odisha, India

Correspondence : Dr. Kulwant Lakra, Email: kulwantlakra@gmail.com

\section{Abstract:}

Introduction: Patient satisfaction is a psychological concept which is considered as a judgment of individuals regarding any object or event after gathering some experiences over time. It is one of the established yardsticks to measure the success of the services. Objectives: 1 . To assess the level of inpatient satisfaction on hospital services. 2. To find out the determinants of inpatient satisfaction on hospital services. Method: It was a cross-sectional study conducted over a period of four months at one of the, a tertiary care hospital in Odisha in eastern India. A total of 164 patients were enrolled in the study from the five most occupied indoor departments who were administered a pre-tested semi-structured standardised questionnaire by face to face interview method. Results: Majority $(77.44 \%)$ of respondents were in the age group of 21-60 years. The sample consisted of $65.24 \%$ males and $43.9 \%$ were from lower socio-economic class. Patient satisfaction level was found to be relatively low $(\sim 80 \%)$ for the service domains like housekeeping, general services and ancillary services. Fields like front desk services, medical care, nursing care and laboratory services enjoyed a better satisfaction score $(\sim 90 \%)$. Binary logistic regression analysis reflected age and socio-economic class to be the negative determinants of the level of satisfaction. Conclusion: About two thirds of the inpatients were satisfied with the services availed at the tertiary care hospital in the five specialities. There is scope of improvement in the areas like housekeeping, ancillary care and general care. Socio-demographic characteristics like age and socioeconomic class inversely related to inpatient satisfaction on hospital services.

Key words: Hospital Services, Patient Satisfaction, Quality of Health Care

\section{Introduction:}

The patient is the ultimate consumer of hospital services. The primary goal of the tertiary care hospital as a highest level of health care provision is to provide best possible health care to the patients. ${ }^{[1]}$ The patient satisfaction level is the real testimony to know the efficiency of hospital administration and is one of the yard stick to measure the success of service it delivers.
Patient satisfaction is multifaceted and a very challenging outcome to define as every individual carries different set of thoughts, feelings and needs. Satisfaction is an important element in the evaluation stage. Patient satisfaction denotes the extent to which health care needs of the clients are met to their requirements. Patients carry certain expectations before their visit to the health facility and the resultant satisfaction or dissatisfaction is the

\begin{tabular}{|c|l|l|}
\hline Quick Response Code & Access this article online & How to cite this article: \\
\hline & Panda SK, Satapathy SP, Panda PC, Lakra K, Karir S, \\
Panda JN. Determinants of Inpatient Satisfaction on \\
Hospital Services in a Government Tertiary Care \\
Center. Healthline.2021;12(2):05-12.
\end{tabular}


outcome of their actual experience. ${ }^{[2]}$ The expectation from healthcare institutions are increasing and level of satisfaction is decreasing, leading to increased number of legal suits and assault on medical professionals. So it is very important to find out the determinants affecting patient satisfaction.

\section{Objectives}

The present study was designed in a tertiary care set up with the objectives, namely:

1. To assess the level of inpatient satisfaction with hospital services.

2. To find out the determinants of inpatient satisfaction with hospital services.

\section{Method:}

\section{Study setting and Design}

It was an institutional based cross sectional study conducted over a period of four months from October-2018 to January-2019 carried out at Veer Surendra Sai Institute of Medical Sciences and Research (VIMSAR) Hospital, a tertiary care academic hospital managed by the state government. The hospital has about eleven hundred beds in sixteen specialities and super speciality departments. It is located at Burla Township in the Sambalpur Municipal Corporation and caters to the ten adjoining districts of the state.

\section{Study population}

As reflected form the hospital records, bed occupancy of the hospital is mainly (76\%) contributed by the departments of General Medicine, General Surgery, Obstetrics \& Gynaecology, Paediatrics and Orthopaedics. The inpatients of these five speciality departments constituted the study population. Only indoor services were evaluated to have a focussed objectivity of the study.

\section{Sample size}

The sample size was determined using the formula for a single population proportion based on the assumptions of $95 \%$ confidence level, $5 \%$ degree of precision and $89 \%$ the proportion of patient satisfaction. ${ }^{[4]}$ Thus the calculated ' $n$ ' was 149 and with a $10 \%$ non-response rate the final sample size was 164. The estimated sample was pooled through equal contributions from each of the five departments and the constituent clinical units.

\section{Sampling technique}

A team of five interns were the investigators who were oriented about the tool and survey in advance. The survey team scheduled their visit to the department indoors twice a week. On any survey day, each of the members of the team visited a selected department and selected unit. Within the unit, out of all the available indoor patients who satisfied the inclusion and exclusion criteria, two patients were enrolled for survey through simple random sampling by lot. The treating doctor and staff were largely kept unaware of the survey to avoid bias towards the patients.

Inclusion criteria: The patients who had completed a minimum hospital stay of 24 hours and were listed to be discharged the next day were included for the study.

Exclusion criteria: Seriously ill, unconscious and mentally incapacitated patients were excluded from the study.

\section{Study tool \& Data collection}

The survey was conducted during the initial two months followed by data compilation, analysis and project writing during the next two months. A semistructured questionnaire was used which was validated by a pilot study on fifty patients. It was administered by the research staff by face to face interview.

The questionnaire had 31 items covering the fields of 'front desk services' (4 items), 'medical care' (4 items), 'nursing care' (4 items), 'laboratory services' (4 items), 'housekeeping services' (4 items), 'general services and care'(4 items), ancillary services ( 7 items). Each of the item had 4 responses in Likert type scale categorised as 'poor (score of 3 or less)', 'fair (score of 4 or 5)', 'good (score of 6 or 7)' and 'excellent (score of 8 to 10)' defined on the basis of the satisfaction score of the respondent in a scale of 1 to 10 (minimum to maximum) assessed by the surveyer. 
Socio-demographic characteristics of the participants were collected. Those included age, gender, occupation, education and income. ${ }^{[3]}$ The following components of hospital services and care were assessed in the survey items.

1. Front desk services included ease of registration, friendliness, efficiency (time) and responsive to needs.

2. Medical care included quality of care, frequency of visits by doctors, explanation of procedures and disease and empathy \& understanding by the staff.

3. Nursing care included professional appearance, availability of nursing staff in the wards, their communication \& behaviour towards patients and timely dispensing of medications.

4. Laboratory services included availability of facilities, behaviour, transit time from bed to laboratory and timely release of lab reports.

5. Housekeeping services included cleanliness of ward, cleanliness of bathroom, cleanliness of public area and condition of linen.

6. General services and care included availability of wheel chair/stretchers, presence of ward attendant/security staff for assistance at entrance/wards, presence of signage and time taken between admission and initiation of treatment.

7. Ancillary services included availability of drinking water in the premises, toilet facilities, hand-wash facility, fans and lights in the wards, availability and quality of hospital diet and waiting space facility for relatives \& attendants.

8. Overall services and care included the average of score of the respondents on the seven determinants as listed above.

\section{Ethical approval}

Prior approval of the institutional ethical committee was obtained for the study. Informed written consent was ensured from the respondents.
Minors and incapacitated patients were represented by the accompanying attendants.

\section{Data management and statistical Analysis}

The data collected was analysed by using SPSS statistical package (version 17.0). Descriptive statistics were performed on the socio-demographic data and Pearson's chi-square test was used to find out the association of satisfaction level among patients with services of various specialities. Furthermore, binary logistic regression model with 95\% Confidence Interval (CI) was used to identify the various determinants of satisfaction for health care services among the patients.

\section{Results:}

Out of the 164 respondents most were in the age group of 21-60 years (Table 1). Males constituted $65.24 \%$ of the respondents. Occupation wise, $35.97 \%$ were unskilled workers, $28.05 \%$ were home-makers and $9.76 \%$ were unemployed. A sizable segment $(43.90 \%)$ was illiterate. $43.90 \%$ of the subjects belonged to lower socio-economic class according to modified Kuppuswamy scale-2016. ${ }^{[3]}$

The patient satisfaction score in the eight enumerated fields were further categorised as 'satisfied' and 'less satisfied'; the former included responses like 'excellent' and 'good' where as the later included 'poor' and 'fair'.

Table 2 reflected the proportion of 'satisfied' and 'less satisfied' in each of the seven fields of assessment. Determinants like front desk services, medical care, nursing care \& laboratory services had a 'satisfied' percentage of $93.89 \%, 91.45 \%, 87.8 \%$ \& $95.11 \%$ respectively. Determinants in housekeeping services, general services \& care and ancillary services demonstrated a lower 'satisfied' percentage of $80.5 \%, 81.08 \%$ and $82.31 \%$ respectively. In total, $78.05 \%$ of the inpatients were 'satisfied' as regard the 'overall services and care' availed in the five departments (Table 4).

In terms of 'medical care' received, as high as $75.6 \%$ of the respondents (Figure 1) were 'satisfied' with the frequency of doctor's visits whereas $63.41 \%$ were 'satisfied' with the empathy and understanding of the health care providers. 
Table 1: Socio-demographic determinants $(n=164)$

\begin{tabular}{|c|c|c|}
\hline Socio-demographic variables & Number & Percentage \\
\hline \multicolumn{3}{|l|}{ Respondent category } \\
\hline Patient & 145 & 88.41 \\
\hline Attendant & 19 & 11.59 \\
\hline \multicolumn{3}{|l|}{ Age of patient in years } \\
\hline Below 20 & 15 & 9.15 \\
\hline $21-40$ & 79 & 48.17 \\
\hline $41-60$ & 48 & 29.27 \\
\hline Above 60 & 22 & 13.41 \\
\hline \multicolumn{3}{|l|}{ Gender } \\
\hline Male & 107 & 65.24 \\
\hline Female & 57 & 34.76 \\
\hline \multicolumn{3}{|l|}{ Education of patient } \\
\hline Illiterate & 72 & 43.90 \\
\hline Primary & 33 & 20.12 \\
\hline Middle & 36 & 21.95 \\
\hline Secondary & 15 & 9.15 \\
\hline Higher Secondary \& Graduation & 8 & 4.88 \\
\hline \multicolumn{3}{|l|}{ Occupation of patient } \\
\hline Unemployed & 16 & 9.76 \\
\hline Skilled & 38 & 23.17 \\
\hline Unskilled & 59 & 35.97 \\
\hline Home-maker & 46 & 28.05 \\
\hline Student & 5 & 3.05 \\
\hline \multicolumn{3}{|c|}{ Socio-economic status of patient* } \\
\hline Upper & 38 & 23.17 \\
\hline Middle (upper-middle \& lower-middle) & 54 & 32.93 \\
\hline Lower (upper-lower \& lower) & 72 & 43.90 \\
\hline
\end{tabular}

[*modified Kuppuswamy scale-2016]

Figure 1: Determinants of satisfaction in Medical Care ( $n=164$ )

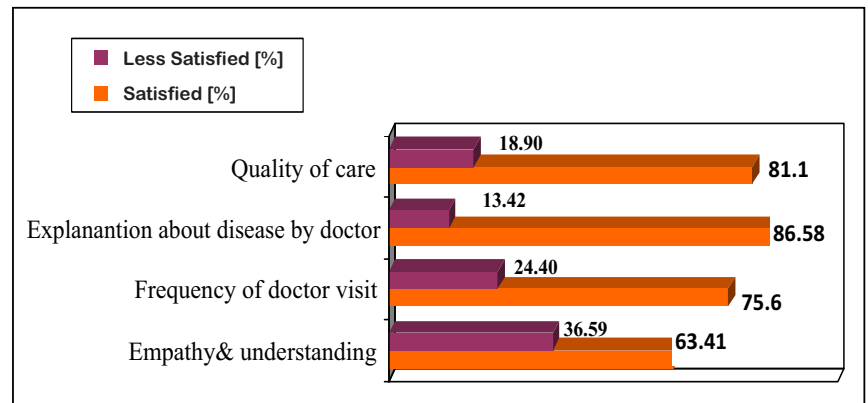

Table 3 highlighted the survey results on laboratory services. $98.17 \%$ of inpatients were 'satisfied' with the availability of laboratory services, 93.3\% with its timeliness (bed to laboratory transit time up to 30 minutes) whereas $31.7 \%$ complained of some delay in getting laboratory reports.

The level of inpatient satisfaction on 'overall services and care' across the five high bed occupancy speciality departments surveyed was tabulated in Table 4. The 'satisfied' proportion ranged between 93.94\% (for Paediatrics) to $54.54 \%$ (for Medicine). In General Surgery, Obstetrics \& Gynaecology and Orthopaedics, $84.85 \%, 78.79 \%$ and $78.12 \%$ of the inpatients were 'satisfied' in that order.

Univariate logistic regression model was applied to interpret age and socio-economic class as determinants of inpatient satisfaction. Those inversely correlated with increasing age $(\mathrm{p}<0.05)$. In the age group of 21-40 years 'less satisfied' level was found to be 1.667 times whereas in $41-60$ years \& beyond 60 years groups, the 'less satisfied' level increased to 4.653 times and 4.881 times respectively. The impact of 'socio-economic status' as a determinant of inpatient satisfaction demonstrated an inverse trend which was statistically significant (Table 5).Variables like gender and education failed to have a statistically significant impact on the satisfaction level.

By adjusting with various other factors it was found on binary logistic regression that age and socio-economic class were the determinants of level of satisfaction among the patients and found to be significant with p value of less than 0.05 (Table 5).

\section{Discussion:}

Patient satisfaction is an important quality outcome indicator to measure success of the services delivery system. Evaluation of care by patients is important to provide opportunity for improvement such as structural reforms, strategic framing of health plans, moulding the human face of the service and investments priorities in order to match the patient expectations. 
Table 2: Determinants in hospital services $(n=164)$

\begin{tabular}{|c|c|c|c|c|}
\hline Services & \multicolumn{1}{|c|}{ Excellent* } & Good* & Fair* & Poor* \\
\hline Front desk services & $102(62.2 \%)$ & $52(31.7 \%)$ & $7(4.3 \%)$ & $3(1.8 \%)$ \\
\hline Medical care & $89(54.3 \%)$ & $61(37.2 \%)$ & $14(8.5 \%)$ & 0 \\
\hline Nursing care & $76(46.3 \%)$ & $68(41.5 \%)$ & $20(12.2 \%)$ & 0 \\
\hline Laboratory services & $92(56.1 \%)$ & $64(39.0 \%)$ & $8(4.9 \%)$ & 0 \\
\hline Housekeeping services & $53(32.3 \%)$ & $79(48.2 \%)$ & $32(19.5 \%)$ & 0 \\
\hline General services \& care & $44(26.8 \%)$ & $89(54.3 \%)$ & $31(18.9 \%)$ & 0 \\
\hline Ancillary services & $61(37.2 \%)$ & $74(45.1 \%)$ & $29(17.7 \%)$ & 0 \\
\hline
\end{tabular}

["Figure in bracket indicates percentage]

Table 3: Determinants in laboratory services $(n=164)$

\begin{tabular}{|c|c|}
\hline Laboratory services variables & Number (\%) \\
\hline Availability of laboratory services & \\
\hline Yes & $161(98.17 \%)$ \\
\hline No & $3(1.83 \%)$ \\
\hline Bed-to-Lab transit time & $37(22.56 \%)$ \\
\hline Below 10 minutes & $116(70.74 \%)$ \\
\hline 10-30 minutes & $11(6.70 \%)$ \\
\hline Beyond 30 minutes & $112(68.29 \%)$ \\
\hline Release time of laboratory reports & $52(31.71)$ \\
\hline Available within scheduled time & \\
\hline Delayed & $123(75.0 \%)$ \\
\hline Quality of care & $41(25.0 \%)$ \\
\hline Satisfactory & \\
\hline Less satisfactory & \\
\hline
\end{tabular}

["Figure in bracket indicates percentage]

Table 4: Association of satisfaction level with speciality services

\begin{tabular}{|c|c|c|c|}
\hline \multirow{2}{*}{ Department [sample size] } & \multicolumn{2}{|c|}{ Satisfaction level* } & \multirow{2}{*}{$\begin{array}{c}\text { Chi-square } \& \\
\text { p-value }\end{array}$} \\
\hline & Satisfied & Less satisfied & \\
\hline Medicine [33] & $18 \quad(54.54 \%)$ & $15(45.46 \%)$ & \multirow{6}{*}{$\begin{array}{l}\chi^{2}=17.872 \\
p=0.001^{* *}\end{array}$} \\
\hline Orthopaedics [32] & $25 \quad(78.12 \%)$ & $\begin{array}{ll}7 & (21.88 \%) \\
\end{array}$ & \\
\hline Obstetrics \& Gynaecology [33] & $26 \quad(78.79 \%)$ & $7 \quad(21.21 \%)$ & \\
\hline General Surgery [33] & $28 \quad(84.85 \%)$ & $5 \quad(15.15 \%)$ & \\
\hline Paediatrics [33] & $31 \quad(93.94 \%)$ & $2 \quad(6.06 \%)$ & \\
\hline Total [164] & $128 \quad(78.05 \%)$ & $36(21.95 \%)$ & \\
\hline
\end{tabular}

[*figure in bracket indicate percentage; ** where $p$ is significant with a value below 0.05] 
Table 5:Binary logistic regression model of determinants of inpatient satisfaction level

\begin{tabular}{|c|c|c|c|c|}
\hline Determinants & Adjusted 0dds Ratio (95\% CI) & p-value & Crude Odds Ratio (95 \% CI ) & p-value \\
\hline Age & Reference (1) & & Reference (1) & \\
\hline Below 20 years & $1.667(0.427-6.511)$ & 0.462 & $2.242(0.456-11.032)$ & 0.321 \\
\hline 21-40 years & $4.653(1.644-13.165)$ & $0.004^{* *}$ & $2.170(0.673-6.997)$ & 0.195 \\
\hline 41-60 years & $4.881(1.529-15.578)$ & $0.007^{* *}$ & $4.242(1.233-14.588)$ & $0.022^{* *}$ \\
\hline Beyond 60 years & $0.190(0.063-0.577)$ & $0.003^{* *}$ & $0.179(0.046-0.699)$ & $0.013^{* *}$ \\
\hline Socioeconomic status* & $0.211(0.071-0.628)$ & $0.005^{* *}$ & $0.264(0.078-0.897)$ & $0.033^{* *}$ \\
\hline $\begin{array}{c}\text { Middle (upper-middle } \\
\text { \& lower-middle) }\end{array}$ & Reference (1) & & Reference (1) & \\
\hline $\begin{array}{c}\text { Lower (upper-lower } \\
\text { \& lower) }\end{array}$ & \multicolumn{2}{|c|}{} & & \\
\hline
\end{tabular}

[ ${ }^{*}$ modified kuppuswamy scale-2016;** where $p$ is significant with a value below 0.05]

The observations reflected that, $43.90 \%$ of the inpatients were from the lower socio-economic class, $32.93 \%$ were from middle class and $23.17 \%$ belonged to upper class. Most of the patients (43.90\%) were illiterate while $14.03 \%$ were having education of secondary level and beyond.

The subject profile in the study in Punjab by Sumeet et al echoed a similar figure (more than half) for education level. Among the respondents there were $10 \%$ unemployed and $90 \%$ belonged to lower socio-economic status group (including lower, upper lower and lower middle class). ${ }^{[1,3]}$

Front desk services, medical care, nursing care \& laboratory services were the most satisfactory services as per the survey with a 'satisfied' proportion between $87.8 \%$ to $93.89 \%$. Determinants like housekeeping services, general services \& care and ancillary services demonstrated a little lower satisfaction percentage of around 80\% (80.5\%$82.31 \%$ ) leaving some scope of attention and improvement.

Kulkarni et al reported that, $87.8 \%$ patients were 'satisfied' with behaviours of doctors whereas a sizable proportion were 'unsatisfied' with quality of food (51.93\%) and availability of drinking water (16.98\%). There, inpatients' feedback was somehow better as regard cleanliness in patients' area, wards and hospital campus $(68.13 \%, 61.85 \%$ and $65.93 \%$ respectively). ${ }^{[5]}$

Bhattacharya et al had reported $98.2 \%$ patients to be satisfied with behaviour of doctors. ${ }^{[6]}$ In our study in terms of 'medical services ' experienced, $75.61 \%$ of the respondents were 'satisfied' with the frequency of visits given by doctors and $64.02 \%$ were 'satisfied' with the empathy and understanding of the staff.

Sharma et al, in their study had concluded that the overall satisfaction regarding the doctor-patient professional and behavioural communication was more than $80 \%$ at almost all the levels of health care facilities. The laboratory staff received a satisfaction level beyond $70 \%$ and more than $80 \%$ were satisfied with basic amenities. ${ }^{[7]}$ These figures somehow matched with the results of our study where $76 \%$ of patients were 'satisfied' with the frequency of doctor's visits and $98.17 \%$ of patients were 'satisfied' with availability of laboratory services. However there was a lower satisfaction level for the ancillary services of the hospital which covered basic amenities.

Goshist et al in Malwa region of Punjab reported about the patients' assessment of the cleanliness of 
the ward areas in a hospital and graded it as poor (38\%), satisfactory (30\%), good (24\%) and excellent $(8 \%) .{ }^{[2]}$ The present survey reported 'excellent' response regarding housekeeping services by about one third (32.31\%) of the participants.

So far the overall impression by the inpatients as regard hospital services in a comprehensive manner is concerned, Kulkarni et al reported a figure of $75.08 \%$, Waseem Qureshi et al reported a figure of 93.3\%, Kaushal et al reported 94.45\%, Jawahar et al $90-95 \%$,Goel et al $77.3 \%$ and Kumari et al $81.6 \%$ in different hospitals across the North Indian States. ${ }^{[5,8-}$ ${ }^{12]}$ The present study in Odisha is in agreement with them with $78.05 \%$ satisfaction level. The subtle difference may be attributed to the differences in the socio-demographic and the socio-cultural differences of the study population and variations in the services delivered.

Males and females as such demonstrated no significant difference in the satisfaction level in our study. Vinod et al had reported a comparable satisfaction level in males(92\%) and females(90\%).

The level of inpatient satisfaction on 'overall services and care' across the five high bed occupancy speciality departments surveyed (Table 4) ranged between $93.94 \%$ (for Paediatrics) to $54.54 \%$ (for Medicine). In General Surgery 84.8\% were 'satisfied' against 78.1\% each in Orthopaedics and Obstetrics \& Gynaecology. With a significant group difference (chisquare value $=17.872$ and $\mathrm{p}=0.001$ ), Paediatrics specialty services had a statistically significant better patient satisfaction score than any of the other speciality services surveyed.

'Age' and 'socio-economic class' emerged as important determinants of patients reflections on the hospital stay and treatment as inferred from univariate and bivariate logistic regression model after adjusting with various factors. It may be explained by the idea that, the older patients with a higher burden of chronic non-communicable disorders somehow received less optimal services due to relatively poorer superspeciality facilities in the hospital concerned. As such the tertiary care hospital lacks dedicated departments like Endocrinology, Cardiothoracic \& Vascular Surgery and Geriatrics Medicine amongst others.

In another study, Vinod et al observed that in the unadjusted models, patients aged beyond 66 years were less likely to rate the overall hospital services 'good' compared with younger patients (OR: 0.47, 95\% CI: 0.25, 0.90). Even after adjusting for other variables this association was not statistically significant (OR: 0.67, 95\% CI: 0.16, 2.74). ${ }^{[13]}$ Another study by Jenkinson et al had suggested that age is not an important factor in the reported satisfaction level. $^{[14]}$

Socio-economic class was found to be inversely related with the satisfaction level in the five speciality services surveyed. Kadri et al had reported similar findings. ${ }^{[4]}$ The study by Ahmed et al had published a contradictory finding, patients with higher income were 2.09 to 2.84 times more satisfied than their counterparts with lower income. ${ }^{[15]}$ The variation may be attributed to differences in the sociocultural attributes of the population studied.

\section{Conclusion:}

About two thirds of the inpatients were satisfied with the services offered at the tertiary care center in the five most occupied speciality indoors. Age and socio-economic class were found to be inversely related with the satisfaction level. Departments of Pediatrics, General Surgery, Obstetrics \& Gynaecology and Orthopaedics received a better feedback from the inpatients against a relatively poorer score for Medicine. There is scope of improvement in ancillary services in terms of amenities like toilets, cleanliness, and drinking water. Laboratory services also leave some scope of improvement in the transit time of samples from bed to laboratory. Availability of wheel chair/stretchers and presence of staff for assistance were the deficiencies which received low satisfaction scores in general care and services.

\section{Recommendation:}

The infrastructural additions of the tertiary health care facility must include better toilet facilities, 
better lighting and ventilation, better sanitation, additional stretchers and wheel chairs. Better security and support staff may be ensured. Periodic training on attitude and communication skills to the health care providers may be imparted.

\section{Limitation:}

The connotation 'satisfaction' is the gap between patient expectations and experience and most often is subjective. A quantitative assessment of health care services in terms of patient experience may be a better tool to monitor health care standards. Thus the validity and usefulness of satisfaction data is limited. A larger sample from multiple centres may yield stronger statistical results.

\section{Declaration:}

Funding: nil

Conflict of interest: nil

\section{Acknowledgement:}

The authors express their sincere appreciation and thanks to the head of the departments of General Medicine, General Surgery, Obstetrics \& Gynaecology, Pediatrics and Orthopaedics at VIMSAR for cooperation.

\section{References:}

1. Singh S, Verma V. Assessing the applicability and usability of patient satisfaction levels as a tool for judging quality of service in a medical college hospital in Punjab, North India [Internet]. International Journal of Public health Research,SeptemberOctober, 2016/ Vol 3/ Issue 5,185-194. [cited 2020 Jul 25].

2. Goshist R, Monga S, Devgan S, Singh B, Gupta S. To study the patient satisfication at a tertiary care hospital in Malwa region of Punjab. Int J Community Med Public Heal [Internet]. 2017 Mar 28 [cited 2020 Jul 25];4(4):1248-52. Available from: http://www.ijcmph.com

3. Khairnar MR, Wadgave U, Shimpi PV. Kuppuswamy's socioeconomic status scale: a revision of occupation and income criteria for 2016. Indian J Pediatr. 2017;84:3-6.

4. Shuja Qadri S, Pathak R, Singh M, Ahluwalia S, Saini S, Garg P. An Assessment of Patients Satisfaction with Services Obtained From a Tertiary Care Hospital in Rural Haryana. Vol. 4, International Journal of Collaborative Research on Internal Medicine \& Public Health. Vol. 4 No. 8 (2012).

5. Kulkarni M V, Dasgupta S, Deoke AR. Study Of Satisfaction Of Patients Admitted In A Tertiary Care Hospital In Nagpur., National Journal Of Community Medicine 2011,Volume 2 , Issue 1,37-39.
6. Bhattacharya A, Menon P, Koushal V. KLNR. Study of Patient Satisfaction in a Tertiary Referral Hospital [Internet]. Journal of the Academy of Hospital Administration.Vol. 15, No. 1 (2003-01 2003-06). [cited 2020 Jul 25].

7. Sumeet S, Paramjeet Kaur RR. Patient satisfaction levels in a tertiary care medical college hospital in Punjab, North India [Internet]. Int J Res Dev Health. November 2013; Vol 1(4): 172 82. [cited 2020 Jul 25].

8. Waseem Q Nazir k, Ajaz N. A case study on patient satisfaction in SMHS hospital, Srinagar. JK Practitioner2005; Vol 12, No.3: 154155.

9. Pushapind, $r$ a K aushal, Sangeeta G , Anurag C , Sarit Sharma MS, Gupta VK, Bansal P. Assessment of Client's Satisfaction Regarding Service Utilization in an Urban Health Centre in Northern India. [Internet]. J of Evolution of Med and Dent Sci/ eISSN- 2278-4802, pISSN- 2278-4748/ Vol. 4/ Issue 58/ July 20, 2015. [cited 2020 Jul 25].

10. Jawahar DSK. A Study on Out Patient Satisfaction at a Super Specialty Hospital in India [Internet]. Internet Journal of Medical Update 2007 Jul-Dec;2(2):13-7. [cited 2020 Jul 25].

11. Kumari R, Idris M, Bhushan V, Khanna A, Agarwal M, Singh S. Study on patient satisfaction in the government allopathic health facilities of Lucknow district, India. Indian J Community Med. 2009 Jan 1;34(1):35-42.

12. Sonu G, Deepak S, Pankaj B. Predictors of Patient Satisfaction in Three Tiers of Health Care Facilities of North India. J Community Med Health Educ [Internet]. 2014 Mar 17 [cited 2020 Jul 25];s2(01):1-5.

13. Vinodkumar S, Varghese BG, Setia MS. Factors associated with patient satisfaction in a private health care setting in India: A cross-sectional analysis. J Hosp Adm. 2018 Jun 13;7(4):44.

14. Jenkinson C, Coulter A, Bruster S, Richards N, Chandola T. Patients' experiences and satisfaction with health care: Results of a questionnaire study of specific aspects of care. Qual Saf Heal Care.2002 Dec;11(4):335-9.

15. Ahmed T, Assefa N, Demisie A. Levels of Adult Patients' Satisfaction with Nursing Care in Selected Public Hospitals in Ethiopia. Int J Health Sci (Qassim). 2014 Dec;8(4):375-83. 